\title{
The Sinorhizobium meliloti EmrAB Efflux System Is Regulated by Flavonoids Through a TetR-Like Regulator (EmrR)
}

\author{
Silvia Rossbach, ${ }^{1,2}$ Kati Kunze, ${ }^{1}$ Susann Albert, ${ }^{1}$ Susanne Zehner, ${ }^{1}$ and Michael Göttfert ${ }^{1}$ \\ ${ }^{1}$ Institute of Genetics, TU Dresden, 01062 Dresden, Germany; ${ }^{2}$ Department of Biological Sciences, Western Michigan \\ University, Kalamazoo, Ml 49008-5410, U.S.A.
}

Submitted 23 September 2013. Accepted 4 November 2013.

The divergently oriented Sinorhizobium meliloti emrAB (SMc03168 and SMc03167) and emrR (SMc03169) genes are predicted to encode an efflux system of the major facilitator superfamily and a TetR-like transcriptional regulator, respectively. The transcription of the $e m r A$ gene was found to be inducible by flavonoids, including luteolin and apigenin, which are known inducers of the nodulation genes in $S$. meliloti. Interestingly, quercetin, which does not induce nodulation genes, was also a potent inducer of $e m r A$, indicating that NodD is not directly involved in regulation of $e m r A$. The likely regulator of $e m r A B$ is EmrR, which binds to palindrome-like sequences in the intergenic region. Several modifications of the palindromes, including an increase of the spacing between the two half sites, prevented binding of EmrR. Binding was also impaired by the presence of luteolin. Mutations in emrA had no obvious effect on symbiosis. This was in contrast to the emrR mutant, which exhibited a symbiotic deficiency with Medicago sativa. Conserved binding sites for TetR-like regulators within the intergenic regions between the $e m r A B$ and $e m r R$ genes were identified in many symbiotic and pathogenic members of the order Rhizobiales.

To cope with antibacterial substances in their environments, bacteria are equipped with a variety of efflux systems, classified as ATP-binding cassette (ABC) superfamily, multidrug and toxic compound extrusion family, small multidrug resistance family, resistance-nodulation-division (RND) superfamily, and major facilitator superfamily (MFS) (Li and Nikaido 2009; Saier and Paulsen 2001). If substances are transported across both membranes in gram-negative bacteria, outer membrane proteins such as TolC and membrane-fusion proteins are also parts of the system (Lewis 2000; Tikhonova et al. 2009; Zgurskaya et al. 2009). Many of the genes encoding efflux pumps, e.g., emrAB of Escherichia coli, are regulated by repressor proteins belonging to the TetR regulator family (Lomovskaya et al. 1995; Ramos et al. 2005). Efflux systems are also required for colonization of eukaryotic hosts (Martinez et al. 2009; Piddock 2006). In Erwinia amylovora and Ralstonia

Corresponding author: S. Rossbach; E-mail: Silvia.Rossbach@wmich.edu; Telephone: +1.269.387.5868; Fax: +1.269.387.5609.

* The $\boldsymbol{e}$-Xtra logo stands for "electronic extra" and indicates one supplementary figure is published online.

(C) 2014 The American Phytopathological Society solanacearum, the inactivation of resistance-nodulation-cell division (RND) systems led to an impaired virulence on apple rootstock and tomato, respectively (Brown et al. 2007; Burse et al. 2004). In Agrobacterium tumefaciens, the RND system Ife $\mathrm{AB}$ is required for competitive root colonization (Palumbo et al. 1998). Efflux systems are also involved in symbiotic interactions, e.g., in members of the Rhizobiaceae family, which are able to symbiotically fix atmospheric nitrogen in the root nodules of legume plants. In Bradyrhizobium japonicum, a deletion of the $b d e A B$ genes, which encode an RND-type efflux system, results in decreased symbiotic nitrogen fixation activity with soybean (Lindemann et al. 2010). In contrast, the deletion of a second RND system encoded by fre $C A B$ did not affect symbiosis with soybean (Wenzel et al. 2012). A systematic study of rhizobial efflux systems was done for Sinorhizobium meliloti, the symbiont of alfalfa (Eda et al. 2011). One ABC-, three MFS-, and 10 RND-type efflux systems as well as three outer membrane proteins, including TolC, were identified as multidrug efflux pumps. Only the TolC mutant exhibited a significant symbiotic defect (Cosme et al. 2008; Eda et al. 2011). Transcriptional analysis revealed that around 1,500 genes are differentially expressed in a TolC mutant strain (Santos et al. 2010). Two of the upregulated genes are SMc03167 and SMc03168, which encode an MFS-type efflux system. Interestingly, in transcriptomic screens, both genes were found to be induced by the flavonoid luteolin (Barnett et al. 2004; Capela et al. 2005). Luteolin is present in the exudate of alfalfa seeds and is known as an inducer of the nodulation genes (Hartwig et al. 1990; Peters et al. 1986). Here, we characterize the flavonoid-inducible expression of SMc03168 (emrA) and show that the putative TetR-like regulator encoded by SMc03169 influences the symbiotic interaction.

\section{RESULTS}

Based on sequence similarity, SMc03167 and SMc03168 genes encode a multidrug efflux system.

The SMc03167 and 03168 genes are located on the S. meliloti chromosome and are predicted to form an operon. Adjacently located but divergently transcribed is $S M c 03169$ (Fig. 1). The protein encoded by SMc03167 belongs to the MFS-type transporters. More specifically, SMc03167 is part of the EmrB/QacA subfamily of multidrug efflux proteins. EmrB from $E$. coli is known to confer resistance to hydrophobic compounds, such as uncouplers, nalidixic acid, and phenyl mercury acetate (Lomovskaya and Lewis 1992). The deduced SMc03167 protein is 529 amino acids long and displays 14 membrane-spanning regions, as predicted by TMpred. The protein encoded by 
SMc03168 exhibits features of a membrane fusion protein and belongs to the EmrA family of multidrug resistance efflux pumps. The deduced SMc03168 protein is 382 amino acids long. The first $35 \mathrm{~N}$-terminal amino acids are predicted to be located inside the cytoplasm, amino acids 36 to 53 represent a single trans-membrane domain, and the remainder of the protein is predicted to be located in the periplasm, which is consistent with its suggested role as membrane fusion protein. The E. coli EmrAB proteins share a considerable number of identical and similar amino acid residues with the gene products of SMc03168 (36 and 50\%, respectively) and of SMc03167 (30 and $49 \%$ ). Therefore, we decided to name SMc03168 emrA and SMc03167 emrB (Fig. 1).

\section{The expression of emrA}

\section{is inducible by different flavonoids.}

Transcriptomic studies had shown that the expression of emrA (SMc03168) and emrB (SMc03167) is induced by the presence of the flavonoid luteolin in the culture medium (Barnett et al. 2004; Capela et al. 2005). The goal was to test whether other flavonoids or related phytoalexins are also able to induce these genes. Previously, a mini-Tn5 (mTn5-STM) transposon, which contains a promoterless gusA reporter gene, was used for mutagenesis of S. meliloti (Pobigaylo et al. 2006). Of several avail- able mutants that carry mTn5-STM insertions in this region, one mutant contained the insertion in the correct orientation to measure the activity of an emrA::gusA transcriptional fusion (Fig. 1). For expression analyses, the mutant was grown for $4 \mathrm{~h}$ with $1 \%$ dimethyl sulfoxide (DMSO) as solvent control or with selected compounds in $100 \mu \mathrm{M}$ concentration. In increasing order, the flavonoids quercetin, luteolin, galangin, naringenin, and apigenin induced the expression of the emrA::gusA fusion between 4.3- to 6.6-fold (Fig. 2). The values obtained with genistein, phloretin, daidzein, and berberine were not significantly different from the values obtained for the solvent control (Fig. 2).

\section{The $S M c 03169$ gene encodes a TetR-like regulator.}

To analyze how the inducibility of the $e m r A B$ genes by different flavonoids is mediated, we focused on the characterization of the adjacent but divergently oriented SMc03169 gene (Fig. 1), for which we propose the designation $e m r R$. The predicted protein encoded by $e m r R$ belongs to the TetR-like regulator family. It exhibits a helix-turn-helix motif at the N-terminal domain. As annotated, EmrR (SMc03169) is a protein of 236 amino acids, but there is no well-conserved ribosomal binding site upstream of the annotated start codon. However, there is a ShineDalgarno-like motif upstream of a CTG that follows 12 codons
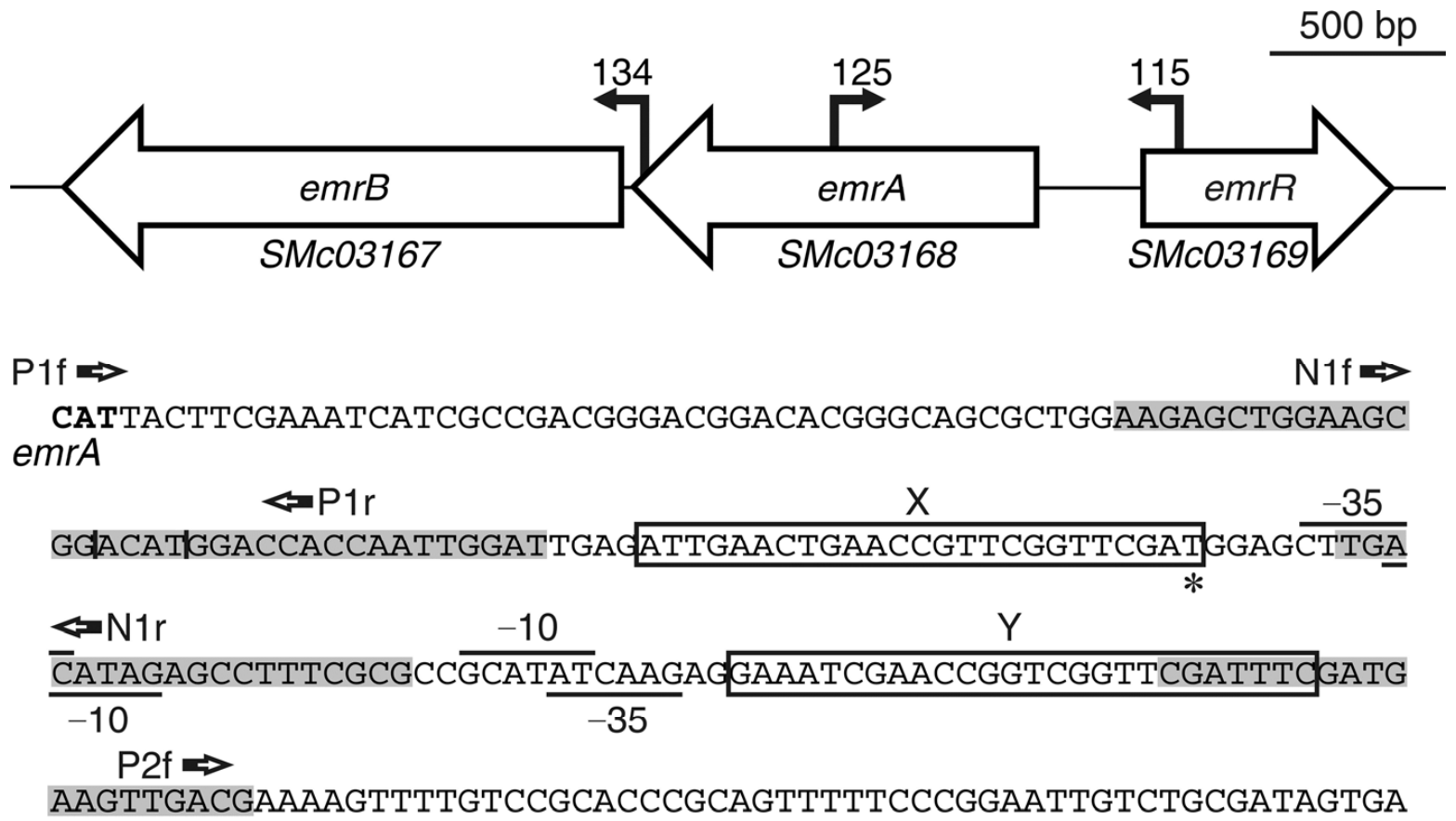

(*) $\nleftarrow \mathrm{P} 2 \mathrm{r}$ TTTTGGACAGAATGCGTCCGCGGTCACCGCGACGCGCGCGATCAAAGGAGTGGATACGTC

\section{emrR \\ CGGCAGCCATGGTATCAGCGAAGAGCGCAGAGCAGGAAAAGACCCTG}

Fig. 1. Map of the SMc03167-SMc03169 (emrBAR) region with its putative regulatory elements. Orientations and sizes of the $e m r A B$ and $e m r R$ open reading frames are denoted at the top of the figure. Numbered arrows above the open reading frames indicate the locations and orientations of the mTn5-STM transposon insertions. The DNA sequence in the lower part of the figure portrays the intergenic region between SMc03168 (emrA) and the SMc03169 (emrR) gene. Putative start codons are indicated in bold. The annotated start codon for emrA is shown on the opposite strand. The annotated ATG start codon for emrR (SMc03169) is shown, as well as the putative CTG start codon, which is preceded by an AG-rich Shine-Dalgarno-like sequence. The two palindromic sequences $\mathrm{X}$ and $\mathrm{Y}$, serving as operators for EmrR, are boxed. Putative 35/-10 promoter elements for $e m r A$ are underlined and, for $e m r R$, indicated by a line above the DNA sequence. Annealing sites for primers used in reverse transcription-polymerase chain reaction experiments are shaded. The designations of the primers are given above the sequence and their orientations are depicted by horizontal arrows. Primer P1f anneals upstream of the shown sequence within the emrA open reading frame. Binding sites for N1f and P1r overlap by four nucleotides, indicated by two vertical lines. Transcriptional start sites as suggested by Schlüter and associates (2013) are marked by asterisks below (for $e m r A$ ) or above (for emrR) the sequence. Our data suggest that the transcriptional start site for $e m r R$ is further upstream. 
further downstream. If this CTG were used as the start codon, $e m r R$ would encode a protein of 224 amino acids. Bioinformatic analysis showed that this size is also more similar to the sizes of related proteins from other members of family Rhizobiaceae (e.g., YP_769756 from Rhizobium leguminosarum bv. viciae, 226 amino acids and YP_002545706 from Agrobacterium tumefaciens, 226 amino acids). To study whether the observed regulation of the $\operatorname{emr} A B$ genes might be mediated through this TetRlike regulator, the emrR gene (starting at the CTG codon) was cloned into the pGEX-4T-3 vector and was expressed as a glutathione $S$-transferase (GST) fusion protein. For purification, the GST was cleaved off with thrombin, resulting in a clean fraction of EmrR, which subsequently was used for electrophoretic mobility shift assays (EMSA).

\section{The TetR-like regulatory protein EmrR binds to conserved palindromic sequences within the intergenic region between $e m r A$ and $e m r R$.}

To test the possible binding of EmrR to regulatory DNA regions, an EMSA was performed with the purified protein and a polymerase chain reaction (PCR) product encompassing the intergenic region between $e m r A$ and $e m r R$. Figure 3 shows that the electrophoretic mobility of the 372-bp long PCR product decreased if it was incubated with increasing concentrations of

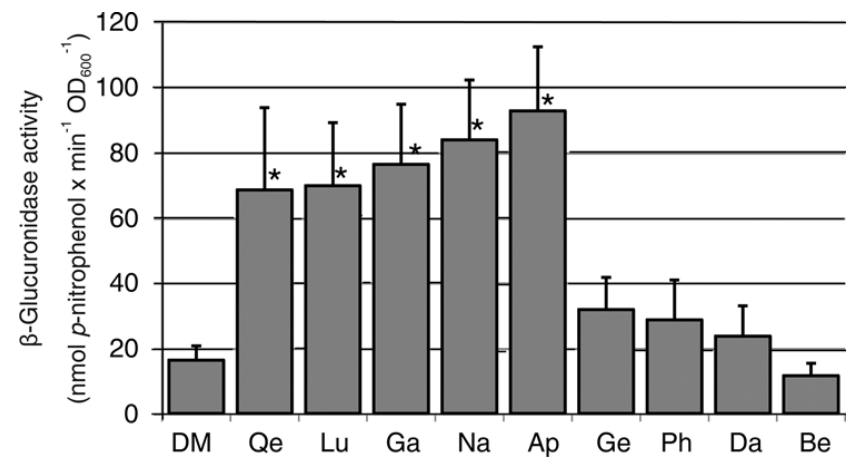

Fig. 2. $\beta$-Glucuronidase activity of the emrA::gusA fusion in the presence of different flavonoids and phytoalexins. The reaction rate of the $\beta$-glucuronidase is expressed as nanomoles $p$-nitrophenol produced per minute and per cell density $\left(\mathrm{OD}_{600}\right) . \mathrm{DM}=$ control culture treated with solvent dimethyl sulfoxide (DMSO); the other cultures were treated with $100 \mu \mathrm{M}$ indicated inducers. $\mathrm{Qe}=$ quercetin, $\mathrm{Lu}=$ luteolin, $\mathrm{Ga}=$ galangin, $\mathrm{Na}=$ naringenin, $\mathrm{Ap}=$ apigenin, $\mathrm{Ge}=$ genistein, $\mathrm{Ph}=$ phloretin, $\mathrm{Da}=$ daidzein , and $\mathrm{Be}=$ berberine. Values were obtained from at least five independent experiments and the standard deviations are indicated. Asterisks denote results that are significantly different from the control culture with DMSO solvent alone $(P<0.01)$.

Table 1. Binding of EmrR to modified palindromic sequences

\begin{tabular}{|c|c|c|}
\hline Oligonucleotid & Sequence $^{a}$ & Shift $^{b}$ \\
\hline \multicolumn{3}{|l|}{ Palindrome $\mathrm{X}$} \\
\hline SR10/11 & GAGATTGAACTGAACCGTTCGGTTCGATGG & + \\
\hline SR32/33 & GAGATTGAACTCTACCGTAGGGTTCGATGG & - \\
\hline SR16/17 & GAGATTGAACTGAACCCCGTTCGGTTCGATGG & - \\
\hline SR28/29 & GAGATCGAACCGAACCGTTCGGTTCGATGG & + \\
\hline SR30/31 & GAGATTGAACTGAACCGTTCAGTTCAATGG & + \\
\hline \multicolumn{3}{|l|}{ Palindrome Y } \\
\hline SR12/13 & GAGGAAATCGAACCGGTCGGTTCGATTTCG & + \\
\hline SR34/35 & GAGGAAATCCTACCGGTCGGTAGGATTTCG & - \\
\hline SR18/19 & GAGGAAATCGAACCGGTGTCGGTTCGATTTCG & - \\
\hline \multicolumn{3}{|c|}{ 30-mer between $\mathrm{X}$ and $\mathrm{Y}$} \\
\hline SR14/15 & CTTGACATAGAGCCTTTCGCGCCGCATATC & - \\
\hline
\end{tabular}

a The palindromic sequences are underlined and the introduced modifications are in bold and italics.

${ }^{\mathrm{b}}$ Shift with EmR. A DNA-protein complex was observed (+) or not observed $(-)$. the purified EmrR protein. Higher protein concentrations resulted in even lower mobility of the DNA-protein complexes (Fig. 3). No electrophoretic mobility shift was observed when a negative control, a PCR product representing the intergenic region between $\operatorname{nod} A B C$ and $\operatorname{nod} D$, was used (data not shown). Inspection of the intergenic region between $e m r A$ and $e m r R$ revealed the presence of two palindromic sequences, which are located $90 \mathrm{bp}$ (operator X) and $150 \mathrm{bp}$ (operator Y) upstream of the start codon of emrA (Fig. 1). To analyze the involvement of the two operator sequences in DNA-protein complex formation, complementary 30-mer oligonucleotides representing both operators were synthesized and used in EMSA (Table 1, SR10/11 and SR12/13). Both double-stranded oligonucleotides were shifted, but interestingly, the DNA-protein complex with operator X exhibited a lower electrophoretic mobility than the one with operator Y (Fig. 4), perhaps representing a different oligomerization state of EmrR.

Between the two operator sites, putative promoter sequences for $e m r R$ and $e m r A$ can be predicted. For S. meliloti, MacLellan and associates (2006) had identified well-conserved sequences for the -35 region (CTTGAC) and, to a lesser extent, for the -10 region (CTATAT), both of which can be found with just a few variations for the divergent promoters of the emrA and emrR genes (Fig. 1). Recently, transcription start sites in $S$. meliloti were mapped using an RNAseq approach (Schlüter et al. 2013). The reported transcription start site for emrA is located within palindrome $\mathrm{X}$ and at an appropriate distance downstream of the predicted -10 region (Fig. 1, indicated by an asterisk). The reported +1 site for $e m r R$ is located more than $100 \mathrm{bp}$ downstream of the predicted -10 region (Fig. 1, indicated by an asterisk in parenthesis). To test if transcription might start further upstream, we isolated total RNA from naringenininduced cultures. After reverse transcription, cDNA was amplified using different primer pairs (Figs. 1 and 5). The primer pair P2f/P2r yielded the predicted 133-bp fragment (Fig. 5), which is in support of the -35 and -10 promoter regions upstream of $e m r R$ as predicted by us. Similarly, the fragment

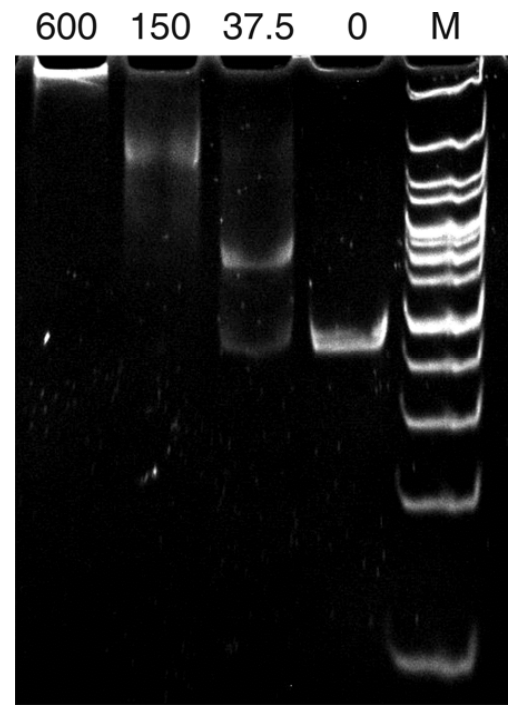

Fig. 3. Electrophoretic mobility shift assay with purified EmrR protein and a 372 -bp-long polymerase chain reaction (PCR) product encompassing the emrA-emrR intervening region. Different amounts of protein, as indicated above the lanes (in nanograms), were incubated with $110 \mathrm{ng}$ of PCR product, were loaded onto a $7 \%$ polyacrylamide gel, were subjected to electrophoresis, and were stained with ethidium bromide. The amount of protein used equaled 25, 6, and 1.5 pmol, respectively, and the amount of DNA was 0.45 pmol. Higher protein concentrations resulted in the formation of DNA-protein complexes of lower mobility. $\mathrm{M}=100 \mathrm{bp}$ DNA plus ladder; $0=$ no protein added. 
obtained with cDNA and primer pair P1f/P1r supports the indicated emrA promoter (Figs. 1 and 5). The annealing site of primer N1r is predicted to be located in a nontranscribed region. Indeed, a PCR fragment with primer pair N1f/N1r was obtained only with genomic DNA but not with cDNA (Fig. 5).

To test if binding sites similar to the operator sequences $\mathrm{X}$ and $\mathrm{Y}$ exist in other bacteria, intergenic regions in between $e m r A$ - and $e m r R$-like genes were analyzed with bioinformatic tools. The alignment of intergenic regions from 40 different species revealed a high conservation of short palindromic sequences, mainly in the order Rhizobiales (Supplementary Fig. $\mathrm{S} 1)$. The palindromes were not only found in symbiotic species but also in plant-pathogenic Agrobacterium species and animal-pathogenic Brucella species, suggesting the presence of similar regulatory mechanisms.

\section{Defining important base pairs for protein-binding.}

The target sequences of the operators were modified to test for specific sequence requirements for binding of EmrR (Table 1). The exchange of GA to $\mathrm{CT}$ in the central GAAC motif, with a corresponding change of TC to AG in the complementary other half of the palindrome, completely abolished complex formation with both operators X and Y (Table 1, SR32/33 and SR34/35, respectively). Moreover, the insertion of two nucleotides in the center of both palindromes abolished complex formation (Table 1, SR16/17 and SR18/19). In contrast to operator sequence $\mathrm{Y}$, which exhibits a perfect symmetry over $24 \mathrm{nt}$, the palindromic sequence in operator $\mathrm{X}$ is interrupted twice by single nucleotides. When nucleotides were exchanged to create the perfect symmetry in operator sequence $X$, either on the left or on the right side of the palindrome, both modifications resulted in strong complex formations (Table 1, SR28/29 and SR30/31). As a negative control, oligonucleotides representing a sequence between the two palindromes $\mathrm{X}$ and $\mathrm{Y}$ were also tested with EmrR, but no DNA-protein complex was visible (Table 1, SR14/15).

\section{Luteolin interferes with DNA-EmrR complex formation.}

We tested whether the presence of flavonoids would inhibit the formation of a DNA-EmrR complex. Indeed, several fla-

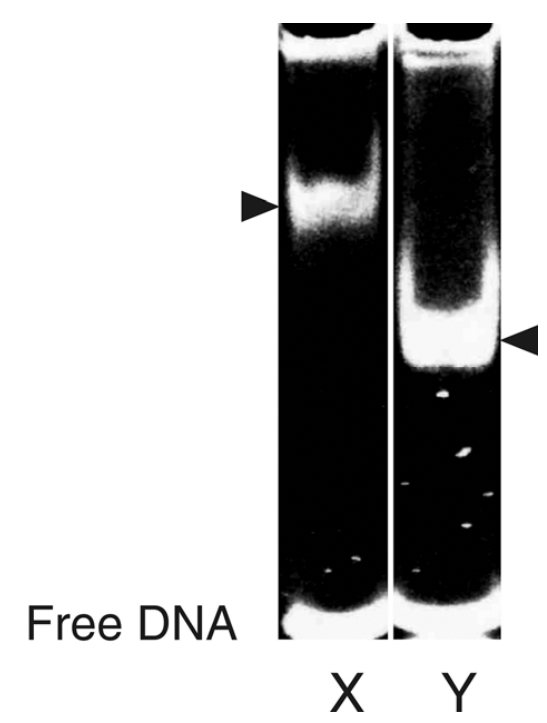

Fig. 4. Electrophoretic mobility shift assay with purified EmrR protein and oligonucleotides representing the two palindromic sequences in the emrAemrR intervening region. $\mathrm{X}$ and $\mathrm{Y}$ represent two complementary oligonucleotides, each with a 30-bp sequence encompassing the palindromic sequences $\mathrm{X}$ and $\mathrm{Y}$, respectively. Arrowheads point to the DNA-protein complexes. Ten picomoles oligonucleotides were used and the amount of protein was $300 \mathrm{ng}$ (12 pmol). vonoids inhibited the formation of the DNA-protein complex. Figure 6 shows that the intensity of the DNA-protein complex diminished and the amount of the free oligonucleotide increased when increasing concentrations of luteolin were added to the reaction. Decreasing complex formations were observed with increasing luteolin concentrations starting at $250 \mu \mathrm{M}$ and the oligonucleotide representing the $\mathrm{X}$ operator (Fig. 6). Similar results were obtained with the oligonucleotide representing the $\mathrm{Y}$ operator and with the PCR product encompassing the complete intergenic region (data not shown). In addition, other flavonoids were tested for their ability to inhibit DNA-protein complex formation. At least partial inhibition of DNA-protein complex formation was observed with apigenin, quercetin, naringenin, daidzein, and genistein (data not shown).

\section{Symbiotic phenotype of the emrA and emrR mutants.}

To test the hypothesis that the presence and correct regulation of the flavonoid-inducible efflux system are required for symbiosis, a plant nodulation assay was performed. Alfalfa plants (Medicago sativa var. Beda) were inoculated with the $S$. meliloti emrA or emrR mutants. As already reported, a mutation of emrA (SMc03168) did not affect symbiosis (Eda et al. 2011). Interestingly, the inoculation of alfalfa with the emrR mutant resulted in small, nitrogen-starved plants with yellow leaves, indistinguishable from the noninoculated control plants (not shown). To obtain quantitative data, the number of nodules and the dry weights of the plants were determined after 33 days of growth (Table 2). The dry weights of the plants inoculated with wild type or emrA mutants were around twice the weights of the noninoculated plants or the plants inoculated with the emrR mutant. Interestingly, both mutant strains and the wild type induced similar nodule numbers.

\section{DISCUSSION}

This study analyzed how the expression of the $S$. meliloti emrAB genes (SMc03167/SMc03168), which are predicted to encode a multidrug efflux pump, is regulated. Many of the efflux pump genes mentioned in the introduction, including the $S$. meliloti emrAB genes described here, are located adjacent to genes encoding TetR-like regulators (Ramos et al. 2005). The regulators bind to palindromic sequences in the promoter region of the genes they regulate, and upon substrate binding, they undergo a conformational change, reducing their affinity to the operator sequences (Ramos et al. 2005). Here, we have unequivocally shown that the purified

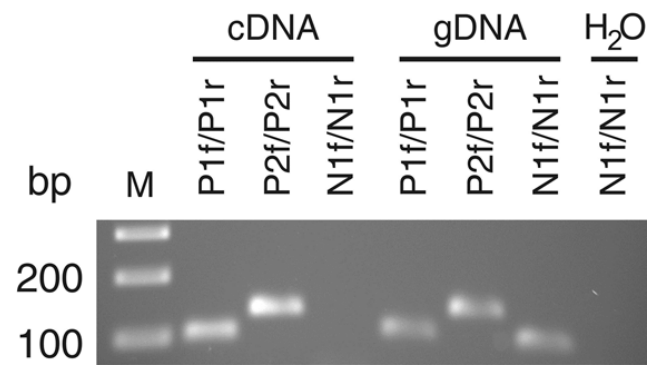

Fig. 5. Expression analysis of the emrA-emrR intergenic region by reverse transcription-polymerase chain reaction (PCR). cDNA or genomic DNA (gDNA) were used as template. In the control reaction $\left(\mathrm{H}_{2} \mathrm{O}\right)$, no template was added. With genomic DNA as template, the expected fragment sizes were $100 \mathrm{bp}$ with primer pair P1f and P1r, $133 \mathrm{bp}$ with primer pair P2f and $\mathrm{P} 2 \mathrm{r}$, and 89 bp with primer pair N1f and N1r. Five microliters of each PCR product was loaded. $M=$ GeneRuler 100 bp Plus DNA ladder (Thermo Fisher Scientific, Waltham, MA, U.S.A.). The results shown here were confirmed by a second independent experiment. 
S. meliloti EmrR binds to the intergenic region between emrR and the divergently encoded $e m r A B$ genes (Fig. 3). More specifically, we showed that EmrR recognizes two palindromic sequences in the intergenic region (Fig. 4). The presence of two operators in the emrAB-emrR intergenic region is not without precedence. There are two operators, tetOl and tetO2, in the tetracycline-resistance locus of E. coli (Saenger et al. 2000) and also two operators in the intergenic region between the fre $C A B$ and the frr $A$ genes in $B$. japonicum, which encode an RND-type efflux system and a TetR-like regulator, respectively (Wenzel et al. 2012).

Interestingly, both palindromes are located directly downstream of the predicted -10 and -35 promoters for the divergently oriented $e m r R$ and $e m r A B$ genes (Fig. 1). Our reverse transcription-PCR experiment suggests that the corresponding downstream regions are transcribed (Fig. 5). The promoter elements originally suggested by MacLellan and associates (2006) were confirmed by Schlüter and associates (2013) for $\sigma^{70}$ dependent promoters. Moreover, the transcription start site for emrA (SMc03168) was recently identified (Schlüter et al. 2013). Therefore, we conclude that the binding of EmrR to the palindromic sequences will inhibit transcription of the emrAB genes and of its own gene, $e m r R$. For $e m r R$, Schlüter and associates (2013) suggested a transcriptional start site further downstream, contradicting our data. However, in the case of $e m r R$, the start site prediction of Schlüter and colleagues was based on only 35 reads, which is close to the cutoff of 30 reads chosen by the authors to reduce false positives. For emrA (SMc03168), the coverage was 160 and indeed, this transcription start site was supported by our data (Fig. 5).

There is some ambiguity concerning the start codon of the emrR gene. The annotated ATG start codon is not preceded by a canonical Shine-Dalgarno sequence, but 36 bp downstream, in the same reading frame, there is an AGGA sequence 7 bases upstream of a CTG codon that could serve as a ribosomal binding site. Nevertheless, the presence of a CTG start codon in bacteria has rarely been reported. The two examples are the repA gene from plasmid P307 and the hda gene encoding a protein involved in replication regulation in $E$. coli (Spiers and Bergquist 1992; Su'etsugu et al. 2008). The determination of the $\mathrm{N}$-terminal sequence of EmrR can prove which start codon (or both?) is being used in vivo. It is inter- esting to note, however, that in our experiments it did not matter which version of the protein was expressed, purified, and used in EMSA, since both were equally able to bind to both operator sequences (S. Albert, S. Rossbach, and M. Göttfert, unpublished observation).

We also showed that the presence of luteolin and other flavonoids inhibited the EmrR-DNA complex formation. Thus, binding of flavonoids released the binding of EmrR to the operators, supporting the notion that EmrR is acting as a repressor. The luteolin concentrations needed in vitro for release of the DNA from the EmrR-DNA complex are higher than the luteolin concentrations present in alfalfa roots (Kapulnik et al 1987). However, the luteolin concentrations used in our experiments (Fig. 6; $10 \mu \mathrm{M}$ up to $2 \mathrm{mM}$ ) are comparable to the effector concentrations used in other in vitro experiments with TetR-like repressors. For example, between $64 \mu \mathrm{M}$ and $1.3 \mathrm{mM}$ ethidium bromide were needed to release the DNA from the Mycobacterium tuberculosis Rv3066 TetR-like repressor (Bolla et al. 2012), 5 to $250 \mu \mathrm{M}$ actinorhodin released ActR of Streptomyces coelicolor (Tahlan et al. 2008), 10 to $80 \mathrm{mM}$ deoxycholate were used for Vibrio cholera BreB (Cerda-Maira et al. 2008), and between $78 \mu \mathrm{M}$ to $2.7 \mathrm{mM}$ of diverse hydrophobic compounds released the Staphylococcus aureus QacR from protein-DNA complexes (Grkovic et al 2003).

Our in vitro data are also supported by the results of our in vivo reporter gene assays. With our assay conditions, the op-

Table 2. Symbiotic phenotype of the Sinorhizobium meliloti emrR and emrA mutants on Medicago sativa

\begin{tabular}{lccc}
\hline Strain & No. of plants $^{\text {a }}$ & Nodules $^{\mathbf{b}}$ & Dry weight $(\mathbf{g})^{\mathbf{c}}$ \\
\hline WT & 43 & $4.87 \pm 1.0$ & $0.0173 \pm 0.000$ \\
Noninoculated & 37 & $0.00 \pm 0.0$ & $0.0080 \pm 0.000$ \\
emrR (M115) & 57 & $4.65 \pm 0.4$ & $0.0095 \pm 0.001$ \\
emrA (M125) & 49 & $5.08 \pm 0.4$ & $0.0159 \pm 0.004$ \\
\hline
\end{tabular}

a Total number of plants from two experiments.

b Values shown per plant \pm standard deviation (SD) calculated from the mean of two experiments.

Dry weight per plant in grams \pm SD. Because of low weights, all plants from one experiment were dried together to determine their dry weight, with the resulting weights divided by the number of plants. SD was calculated from the mean of two experiments.



Fig. 6. Electrophoretic mobility shift assay with purified EmrR protein, 30-bp oligonucleotides representing palindrome $\mathrm{X}$ and increasing concentrations of the flavonoid luteolin. The presence $(+)$ or absence $(-)$ of luteolin, dimethyl sulfoxide (DMSO) solvent and EmrR protein is indicated above the gel picture. Luteolin concentrations were, from left to right, as indicated by the wedge, 10, 50, 100, 250, 500, 750 $\mu \mathrm{M}$, and 1, 1.5, and 2 mM, respectively; 200 ng protein $(8.2 \mathrm{pmol})$ and $1.25 \mathrm{pmol}$ oligonucleotides were used. The arrowhead points to the DNA-protein complex. 
timal luteolin concentration for emrA induction was $100 \mu \mathrm{M}$. Likewise, $100 \mu \mathrm{M}$ is also the concentration that Grkovic and associates (2003) found to be optimal for the berberin-mediated induction of a QacR-regulated gene fusion in Staphylococcus aureus. In concentrations several magnitudes lower, luteolin is one of the well-known inducers of the $S$. meliloti nodulation (nod) genes for which the transcriptional activator protein NodD is essential (Hartwig et al 1990; Peters et al. 1986). The different luteolin concentrations needed for nod gene induction compared with the concentrations needed for the induction of $e m r A B$ might reflect different assay conditions but also the involvement of two different signaling pathways.

Not only luteolin, which previously had been found through transcriptomic studies to induce the emrAB genes (Barnett et al. 2004; Capela et al. 2005) but also the related flavonoids apigenin, naringenin, galangin, and quercetin increased the expression of the emrA: :gusA fusion (Fig. 2). The fact that quercetin does not induce the $S$. meliloti nod genes (Peters et al. 1986) is another argument for the NodD-independent regulation of emrAB. Luteolin and also other flavonoids and their conjugated derivatives have been shown to be exuded by Medicago sativa seeds (Hartwig et al. 1990; Peters et al. 1986). These flavonoids, as is probably true for many substances excreted from plant roots, can structure the microbial community in the rhizosphere by either stimulating or inhibiting the growth of different bacterial species. This notion is supported by the results of Hartwig and associates (1991), who showed that luteolin and quercetin enhance the growth of $S$. meliloti in minimal medium while formononetin delays it. Also, the soybeanderived isoflavonoid glyceollin caused a lag phase in the growth of B. japonicum (Parniske et al. 1991). Thus, it is not surprising that, in several plant-associated bacteria, various flavonoid- and phytoalexin-inducible efflux systems have been found to be involved in competitive fitness during symbiotic or virulent plant-bacteria interactions (Burse et al. 2004; GonzálezPasayo and Martínez-Romero 2000; Palumbo et al. 1998). For example, a Rhizobium etli mutant with an insertion in rmrA (an ortholog of the $S$. meliloti emrA gene) was found to induce $40 \%$ fewer nodules on bean plants than the wild type (GonzálezPasayo and Martínez-Romero 2000). Also, an Erwinia amylovora strain with an insertion in the $a c r B$ gene, encoding a component of an RND efflux system, was less virulent than the wild type when infecting apple rootstocks (Burse et al. 2004).

The studies mentioned above analyzed bacterial strains with mutations in the efflux genes themselves. In our work, the $S$. meliloti emrA mutant did not display any obvious symbiotic defects, but the $S$. meliloti emrR mutant clearly had a reduced ability to promote plant growth (Table 2). The $S$. meliloti emrR mutant, independently constructed by Santos and associates (2013), displays the same symbiotic defect on alfalfa that we describe here. How can the phenotype be explained? EmrR might regulate other genes in the genome of $S$. meliloti that have not yet been identified. It is known that some members of the TetR family are part of complex regulatory systems (Ramos et al. 2005). For example, the Neisseria gonorrhoeae TetR regulator MtrR does not only repress the $m t r C$, $m t r D$, and $m t r E$ genes encoding an efflux pump but also the transcription of the regulatory gene farR (Lee et al. 2003). Moreover, MtrR directly or indirectly modulated the expression of ponA, encoding penicillin-binding protein 1 and the pilM, pilN, pilO, pilP, and pil $Q$ genes encoding components of the type IV pilus secretion system (Folster et al. 2007). With respect to EmrR-binding sites in S. meliloti, we could not find other sites with high similarity to the palindromic sequences identified in the emrAemrR intergenic region (S. Rossbach and M. Göttfert, unpublished results). Therefore, genes putatively regulated by EmrR other than $e m r A B$ are not immediately apparent. An alternative explanation is that the mutation in emrR results in overexpression of $e m r A B$, which, in turn, might lead to the symbiotic defect as observed with the emrR mutant. We are not aware of published data that would indicate that an upregulated efflux system prevents efficient symbiosis.

Taken together, the TetR-like regulator EmrR seems to play an important role in establishing a successful interaction of $S$. meliloti with its host plants. The emrAB-emrR system is highly conserved almost exclusively in the order Rhizobiales. Many genera of the Rhizobiales are known to interact with eukaryotes, either in mutualistic or parasitic relationships. It will be interesting to elucidate if the orthologous emrR genes will show similar functions in related symbiotic or pathogenic species.

\section{MATERIALS AND METHODS}

\section{Bacterial strains and plasmids used.}

Bacterial strains and plasmids used in this study are listed in Table 3.

\section{Media and growth conditions.}

E. coli strains were grown in LB medium (Sambrook and Russel 2001) at $37^{\circ} \mathrm{C}$, and $S$. meliloti strains in tryptone-yeast (TY) medium at $28^{\circ} \mathrm{C}$ (Beringer 1974). Antibiotics used were ampicillin $(100 \mu \mathrm{g} / \mathrm{ml})$, streptomycin $(250 \mu \mathrm{g} / \mathrm{ml})$ and kanamycin $(200 \mu \mathrm{g} / \mathrm{ml})$. Flavonoids and phytoalexins were purchased from TransMIT (Project Division for Plant Metabolites and Chemicals, Giessen, Germany).

\section{$\boldsymbol{\beta}$-glucuronidase activity.}

Cells of $S$. meliloti were grown in TY until the optical density at $600 \mathrm{~nm}\left(\mathrm{OD}_{600}\right)=0.15$ to 0.2 , when flavonoids or phytoalexins were added to a final concentration of $100 \mu \mathrm{M}$. After

Table 3. Bacterial strains and plasmids

\begin{tabular}{|c|c|c|}
\hline Strain or plasmid & Genotype, description ${ }^{a}$ & Reference or source \\
\hline \multicolumn{3}{|c|}{ Sinorhizobium meliloti } \\
\hline Sm2011 & Wild type, $\mathrm{Sm}^{\mathrm{r}}$ derivative of SU47 & Meade and Signer 1977 (herein designated Rm2011) \\
\hline 115 & 2011mTn5STM.2.12.A07, SMc03169::mTn5-STM, Smr; Km ; gusA & Pobigaylo et al. 2006 \\
\hline 125 & 2011mTn5STM.4.06.D08, SMc03168::mTn5-STM, $\mathrm{Sm}^{\mathrm{r}} ; \mathrm{Km}^{\mathrm{r}} ;$ gusA & Pobigaylo et al. 2006 \\
\hline 134 & 2011mTn5STM.4.13.C05, SMc03168::mTn5-STM, Smr; Km ${ }^{\mathrm{r}}$ gusA & Pobigaylo et al. 2006 \\
\hline \multicolumn{3}{|l|}{ Escherichia coli } \\
\hline DH10B & 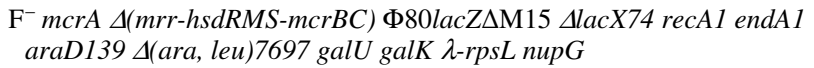 & Invitrogen, Carlsbad, CA,U.S.A. \\
\hline BL21(DE3) & $\mathrm{F}^{-}$ompT hsd $S_{\mathrm{B}}\left(\mathrm{r}_{\mathrm{B}}^{-} \mathrm{m}_{\mathrm{B}}^{-}\right)$gal dcm $\lambda(\mathrm{DE} 3)$ & Invitrogen \\
\hline \multicolumn{3}{|l|}{ Plasmid } \\
\hline pGEX-4T-3 & Vector for generation of $g s t$ fusions, $\mathrm{Ap}^{\mathrm{r}}$ & GE Healthcare, Chalfont St. Giles, U. K. \\
\hline pSM3169s & pGEX-4T-3 containing 675-bp fragment of $S M c 03169, \mathrm{Ap}^{\mathrm{r}}$ & This work \\
\hline
\end{tabular}

${ }^{\mathrm{a}} \mathrm{Sm}^{\mathrm{r}}, \mathrm{Km}^{\mathrm{r}}$, and $\mathrm{Ap}^{\mathrm{r}}$ indicate streptomycin, kanamycin, and ampicillin resistance. 
$4 \mathrm{~h}$, when the $\mathrm{OD}_{600}$ was between 0.3 and $0.5,300 \mu \mathrm{l}$ of culture were pelleted by centrifugation and were resuspended in $600 \mu \mathrm{l}$ of GEB buffer ( $50 \mathrm{mM}$ sodium phosphate buffer, $\mathrm{pH} 7$, $10 \mathrm{mM}$ EDTA, 0,1\% Triton X100, 0.1\% Na-lauroylsarcosine, $10 \mathrm{mM} \beta$-mercaptoethanol). After $15 \mathrm{~min}$ of prewarming at $37^{\circ} \mathrm{C}, 60 \mu \mathrm{l}$ of $20 \mathrm{mM}$ 4-nitrophenyl $\beta$-D-glucuronide (PNPG) were added as substrate. The reaction was stopped at three different time points by adding $330 \mu \mathrm{l}$ of $1 \mathrm{M} \mathrm{Na}_{2} \mathrm{CO}_{3}$. After a short centrifugation, the $\mathrm{OD}_{405}$ of the reaction was determined spectrophotometrically, and the reaction rate was expressed in nanomoles $p$-nitrophenol produced per minute $\times$ cell density $\left(\mathrm{OD}_{600}\right)$. For statistical analysis of the values, a one-way analysis of variance with a Dunnett post-test using DMSO as the control was chosen.

\section{Heterologous expression \\ of $e m r R$ as GST fusion protein.}

The emrR (SMc03169) gene was amplified with primers 03169F2 (5'ATAATGAATTCTATGCAGGATCGGCTGGAG CATC) and 03169R (5'ATAATGTCGACTTACTCCTTGC CGGTCGTCTTTC), and the resulting PCR product was cloned into pGEX-4-T3. The insert of the resulting plasmid (pSM3169s) was verified by sequencing and pSM3169s was transformed into E. coli BL21(DE3). For the purification of the EmrR protein, expression was induced for $4 \mathrm{~h}$ by isopropyl- $\beta$-D-thiogalactoside $(100 \mu \mathrm{M})$. Cells from a $200-\mathrm{ml}$ culture were harvested and resuspended in $3 \mathrm{ml}$ of $\mathrm{TKE}_{100}$ buffer (100 mM Tris, $200 \mathrm{mM} \mathrm{KCl,} 10 \mathrm{mM}$ EDTA, pH 7.5) with $0.1 \%$ lysozyme. Cells were sonicated three times for 10 $\mathrm{s}$ at $60 \%$ power (Sonopuls UW2070, Bandelin Electronic, Berlin), and the EmrR protein was purified using a column containing PrepEase protein purification glutathion agarose 4B (Affymetrix, Santa Clara, CA, U.S.A.). GST was removed by on-column cleavage with thrombin according to the supplier's protocol (GE Healthcare, Chalfont St. Giles, U.K.). EmrR was eluted with $\mathrm{TKE}_{100}$ buffer containing glutathione (15 mM).

\section{EMSA.}

The 372-bp-long PCR product used for EMSA was created by using the primers $5^{\prime}$ CTCGGCCGAATGAGTATCCAT and 5'GATCCTGCAGGGTCTTTTCCT. To create double-stranded operator fragments, complementary oligonucleotides (Table 1) were annealed by incubating at $95^{\circ} \mathrm{C}$ for $5 \mathrm{~min}$ and slowly cooling to room temperature. EmrR was incubated with either PCR product or annealed oligonucleotides in binding buffer (phosphate buffered saline with $1 \mathrm{mM}$ dithiothreitol, $1 \mathrm{mM}$ EDTA, $5 \%$ glycerol, and bovine serum albumin at $0.4 \mathrm{mg} / \mathrm{ml}$ ) for $30 \mathrm{~min}$ on ice, before separation on a $7 \%$ polyacrylamide gel. Electrophoresis was carried out in $0.5 \times$ TBE buffer $(44.5$ $\mathrm{mM}$ Tris, $44.5 \mathrm{mM}$ boric acid, $2 \mathrm{mM}$ EDTA, $\mathrm{pH} 8.3$ ) at $90 \mathrm{~V}$ for 2 to $3 \mathrm{~h}$ on ice. Before imaging, gels were stained with ethidium bromide.

\section{RNA isolation, cDNA synthesis, and reverse transcription PCR.}

RNA isolation and cDNA synthesis were done similar to that described by Hauser and associates (2007). Cells were grown in TY medium containing streptomycin $(100 \mu \mathrm{g} / \mathrm{ml})$ until $\mathrm{OD}_{600}$ was approximately 1.7 . Four $\mathrm{ml}$ of this culture were transferred into $40 \mathrm{ml}$ of TY medium supplemented with naringenin (100 $\mu \mathrm{M}$ final concentration). Cells were grown for $4 \mathrm{~h}$ at $28^{\circ} \mathrm{C}$. The culture was transferred into cold tubes containing $4 \mathrm{ml}$ of stop solution (10\% water-saturated phenol in ethanol, prechilled at $-20^{\circ} \mathrm{C}$ ) and was mixed by inversion. After centrifugation for $5 \min \left(5,445 \times g, 4^{\circ} \mathrm{C}\right)$, the supernatant was decanted and the pellet was immediately frozen in liquid nitrogen and stored at $-60^{\circ} \mathrm{C}$. For RNA isolation, the cell pellet was resuspended in $1.5 \mathrm{ml}$ of buffer $\mathrm{A}$ (0.02 $\mathrm{M}$ sodium acetate, $\mathrm{pH}$ 5.5, 0.01 M EDTA). The suspension was thoroughly mixed with $5.5 \mathrm{ml}$ of preheated $\left(65^{\circ} \mathrm{C}\right)$ acid phenol solution (phenol buffered with buffer A) and 160 $\mu \mathrm{l}$ of $10 \%$ sodium dodecyl sulfate for about $30 \mathrm{~s}$ and was incubated at $65^{\circ} \mathrm{C}$ for $2 \mathrm{~min}$. The solution was vortexed for 1 min and was further incubated at $65^{\circ} \mathrm{C}$ for $5 \mathrm{~min}$. After centrifugation for $5 \mathrm{~min}\left(8,422 \times g, 4^{\circ} \mathrm{C}\right)$, the supernatant was extracted with $3 \mathrm{ml}$ of phenol-chloroform-3-methyl-1-butanol (29:29:1) solution and, subsequently, with $3 \mathrm{ml}$ of chloroform. After centrifugation $\left(8,422 \times g, 4^{\circ} \mathrm{C}\right), 0.1$ volume of $3 \mathrm{M}$ sodium acetate $(\mathrm{pH} 5.5)$ and 2 volumes of ethanol were added and mixed and the solution was frozen in liquid nitrogen. After incubation for $2 \mathrm{~h}$ at $-70^{\circ} \mathrm{C}$, the RNA was pelleted by centrifugation $\left(60 \mathrm{~min}, 20,800 \times g, 4^{\circ} \mathrm{C}\right)$ and was washed with ice-cold $80 \%$ ethanol. The RNA pellet was air dried and dissolved in $100 \mu \mathrm{l}$ of RNase free water. About $100 \mu \mathrm{g}$ of RNA were treated with 10 units of RQ1 DNase I (Promega, Madison, WI, U.S.A.) for $30 \mathrm{~min}$ at $37^{\circ} \mathrm{C}$ in the presence of 30 U RNaseIn Plus (Promega). After DNase treatment, RNA was further purified using RNeasy spin columns (Qiagen, Hilden, Germany). The obtained RNA was analyzed by agarose gel electrophoresis. To test for genomic DNA contamination, a PCR using $2 \mu \mathrm{g}$ of the purified RNA and primers P1f (CTCGGCCGAATGAGTATCC) and P3R (CCGAACGG TTCAGTTCAATC) was performed. For cDNA synthesis, $5 \mu \mathrm{g}$ of RNA were used in a total volume of $25 \mu \mathrm{l}$ using $400 \mathrm{U}$ MMLV reverse transcriptase, RNase $\mathrm{H}$ minus (Promega). Specific cDNA was generated using 7 pmol of each primer, RT3168 (CCACCAATCATAGCCGTACC) and RT3169a (AA ACTGCTCCGCATGAAAAC). Primers anneal in SMc03168 and $S M c 03169$, respectively. The cDNA synthesis reaction was done according to the manufacturer's protocol (Promega). Subsequently, the RNA was degraded by the addition of 0.25 $\mathrm{M} \mathrm{NaOH}\left(30 \mathrm{~min}, 65^{\circ} \mathrm{C}\right.$ ) and was neutralized with $0.25 \mathrm{M}$ $\mathrm{HCl}$. The cDNA was further purified using the MinElute kit (Qiagen).

For PCR analysis, primers P1f (sequence noted above), P1r (ATCCAATTGGTGGTCCATGT), P2f (CGATTTCGATGAA GTTGACG), P2r (CGGACGTATCCACTCCTTTG), N1f (AA GAGCTGGAAGCGGACAT) and N1r (CGCGAAAGGCTC TATGTCA) were used with DreamTaq DNA Polymerase (Thermo Fisher Scientific, Waltham, MA, U.S.A.) and standard PCR conditions.

\section{Plant inoculation assays.}

Medicago sativa cv. Beda seeds (Kiepenkerl, Münster, Germany) were surface-sterilized by submersion for $30 \mathrm{~min}$ in $70 \%$ ethanol and three washes with sterile $\mathrm{H}_{2} \mathrm{O}$, followed by $30 \mathrm{~min}$ in $6 \%$ sodium hypochlorite and five washes with sterile $\mathrm{H}_{2} \mathrm{O}$. Seeds were germinated on folded Whatman 3MM paper $(80 \times 40 \mathrm{~mm})$ that had been put into $25 \times 200 \mathrm{~mm}$ glass tubes and soaked with $20 \mathrm{ml}$ of B\&D nitrogen-free plant nutrient solution (Broughton and Dilworth 1971). After 5 to 7 days of germination, plants were inoculated with $1 \mathrm{ml}$ of media-free rhizobial cultures. Plants were grown in a growth chamber (Sanyo MRL-350; Sanyo Electric Co., Moriguchi City, Osaka, Japan) with a light and dark cycle of, respectively, 16 and $8 \mathrm{~h}$ at 23 and $18^{\circ} \mathrm{C}$.

\section{Bioinformatics.}

For retrieval of protein sequences and BLAST searches (Johnson et al. 2008), the resources of the National Center for Biotechnology Information were used. The operon prediction for SMc03167 and SMc03168 was retrieved from MicrobesOnline (Dehal et al. 2010; Price et al. 2005). The deduced protein 
sequences were analyzed for transmembrane helices with the TMpred tool of the ExPASy SIB Bioinformatics Resource Portal (Artimo et al. 2012).

\section{ACKNOWLEDGMENTS}

We thank M. Weishaupt for technical assistance, A. Becker for providing $S$. meliloti strains, and two anonymous reviewers for helpful comments. This work was supported by the Deutsche Forschungsgemeinschaft through a Mercator Fellowship.

\section{LITERATURE CITED}

Artimo, P., Jonnalagedda, M., Arnold, K., Baratin, D., Csardi, G., de Castro, E., Duvaud, S., Flegel, V., Fortier, A., Gasteiger, E., Grosdidier, A., Hernandez, C., Ioannidis, V., Kuznetsov, D., Liechti, R., Moretti, S., Mostaguir, K., Redaschi, N., Rossier, G., Xenarios, I., and Stockinger, H. 2012. ExPASy: SIB bioinformatics resource portal. Nucleic Acids Res. 40:W597-603.

Barnett, M. J., Toman, C.J., Fisher, R. F., and Long, S. R. 2004. A dualgenome symbiosis chip for coordinate study of signal exchange and development in a prokaryote-host interaction. Proc. Natl. Acad. Sci U.S.A. 101:16636-16641.

Beringer, J. E. 1974. R factor transfer in Rhizobium leguminosarum. J. Gen. Microbiol. 84:188-198.

Bolla, J. R., Do, S. V., Long, F., Dai, L., Su, C. C., Lei, H. T., Chen, X., Gerkey, J. E, Murphy D. C., Rajashankar, K. R., Zhang, Q., and Yu, E. W. 2012. Structural and functional analysis of the transcriptional regulator Rv3066 of Mycobacterium tuberculosis. Nucleic Acids Res. 40:9340-9355.

Broughton, W. J., and Dilworth, M. J. 1971. Control of leghaemoglobin synthesis in snake beans. Biochem. J. 125:1075-1080.

Brown, D. G., Swanson, J. K., and Allen, C. 2007. Two host-induced Ralstonia solanacearum genes, acrA and $\operatorname{din} F$, encode multidrug efflux pumps and contribute to bacterial wilt virulence. Appl. Environ. Microbiol. 73:2777-2786

Burse, A., Weingart, H., and Ullrich, M. S. 2004. The phytoalexin-inducible multidrug efflux pump AcrAB contributes to virulence in the fire blight pathogen, Erwinia amylovora. Mol. Plant-Microbe Interact. 17:43-54.

Capela, D., Carrere, S., and Batut, J. 2005. Transcriptome-based identification of the Sinorhizobium meliloti NodD1 regulon. Appl. Environ. Microbiol. 71:4910-4913.

Cerda-Maira, F. A., Ringelberg, C. S, and Taylor, R. K. 2008. The bile response repressor BreR regulates expression of the Vibrio cholerae bre $A B$ efflux system operon. J. Bacteriol. 190:7441-7452.

Cosme, A. M., Becker, A., Santos, M. R., Sharypova, L. A., Santos, P. M., and Moreira, L. M. 2008. The outer membrane protein TolC from Sinorhizobium meliloti affects protein secretion, polysaccharide biosynthesis, antimicrobial resistance, and symbiosis. Mol. Plant-Microbe Interact. 21:947-957.

Dehal, P. S., Joachimiak, M. P., Price, M. N., Bates, J. T., Baumohl, J. K., Chivian, D., Friedland, G. D., Huang, K. H., Keller, K., Novichkov, P. S., Dubchak, I. L., Alm, E. J., and Arkin, A. P. 2010. MicrobesOnline: An integrated portal for comparative and functional genomics. Nucleic Acids Res. 38:D396-D400.

Eda, S., Mitsui, H., and Minamisawa, K. 2011. Involvement of the SmeAB multidrug efflux pump in resistance to plant antimicrobials and contribution to nodulation competitiveness in Sinorhizobium meliloti. Appl. Environ. Microbiol. 77:2855-2862.

Folster, J. P., Dhulipala, V., Nicholas, R. A., and Shafer, W. M. 2007. Differential regulation of ponA and pilMNOPQ expression by the MtrR transcriptional regulatory protein in Neisseria gonorrhoeae. J. Bacteriol. 189:4569-4577.

González-Pasayo, R., and Martínez-Romero, E. 2000. Multiresistance genes of Rhizobium etli CFN42. Mol. Plant-Microbe Interact. 13:572577.

Grkovic, S., Hardie, K. M., Brown, M. H., and Skurray, R. A. 2003. Interactions of the QacR multidrug-binding protein with structurally diverse ligands: Implications for the evolution of the binding pocket. Biochemistry 42:15226-15236.

Hartwig, U. A., Maxwell, C. A., Joseph, C. M., and Phillips, D. A. 1990. Chrysoeriol and luteolin released from alfalfa seeds induce nod genes in Rhizobium meliloti. Plant. Physiol. 92:116-122.

Hartwig, U. A., Joseph, C. M., and Phillips, D. A. 1991. Flavonoids released naturally from alfalfa seeds enhance growth rate of Rhizobium meliloti. Plant. Physiol. 95:797-803.

Hauser, F., Pessi, G., Friberg, M., Weber, C., Rusca, N., Lindemann, A.,
Fischer, H.-M., and Hennecke, H. 2007. Dissection of the Bradyrhizobium japonicum $\mathrm{NifA}+\operatorname{sigma}^{54}$ regulon, and identification of a ferredoxin gene $(f d x N)$ for symbiotic nitrogen fixation. Mol. Genet. Genomics. 278:255-271.

Johnson, M., Zaretskaya, I., Raytselis, Y., Merezhuk, Y., McGinnis, S., and Madden, T. L. 2008. NCBI BLAST: A better web interface. Nucleic Acids Res. 36:W5-9.

Kapulnik, Y., Joseph, C. M., and Phillips, D. A. 1987. Flavone limitations to root nodulation and symbiotic nitrogen fixation in alfalfa. Plant Physiol. 84:1193-1196.

Lee, E. H., Rouquette-Loughlin, C., Folster, J. P., and Shafer, W. M. 2003. FarR regulates the far $A B$-encoded efflux pump of Neisseria gonorrhoeae via an MtrR regulatory mechanism. J. Bacteriol. 185:7145-7152.

Lewis, K. 2000. Translocases: A bacterial tunnel for drugs and proteins. Curr. Biol. 10:R678-681.

Li, X. Z., and Nikaido, H. 2009. Efflux-mediated drug resistance in bacteria: An update. Drugs 69:1555-1623

Lindemann, A., Koch, M., Pessi, G., Müller, A. J., Balsiger, S., Hennecke, H., and Fischer, H.-M. 2010. Host-specific symbiotic requirement of BdeAB, a RegR-controlled RND-type efflux system in Bradyrhizobium japonicum. FEMS (Fed. Eur. Microbiol. Soc.) Microbiol. Lett. 312:184191.

Lomovskaya, O., and Lewis, K. 1992. emr, an Escherichia coli locus for multidrug resistance. Proc. Natl. Acad. Sci. U.S.A. 89:8938-8942.

Lomovskaya, O., Lewis, K., and Matin, A. 1995. EmrR is a negative regulator of the Escherichia coli multidrug resistance pump EmrAB. J. Bacteriol. 177:2328-2334.

MacLellan, S. R., MacLean, A .M., and Finan, T. M. 2006. Promoter prediction in the rhizobia. Microbiology 152:1751-1763.

Martinez, J. L., Sánchez, M. B., Martínez-Solano, L., Hernandez, A. Garmendia, L., Fajardo, A., and Alvarez-Ortega, C. 2009. Functional role of bacterial multidrug efflux pumps in microbial natural ecosystems. FEMS (Fed. Eur. Microbiol. Soc.) Microbiol. Rev. 33:430-449.

Meade, H. M., and Signer, E. R. 1977. Genetic mapping of Rhizobium meliloti. Proc. Natl. Acad. Sci. U.S.A. 74:2076-2078.

Palumbo, J. D., Kado, C. I., and Phillips, D. A. 1998. An isoflavonoidinducible efflux pump in Agrobacterium tumefaciens is involved in competitive colonization of roots. J. Bacteriol. 180:3107-3113.

Parniske, M., Ahlborn, B., and Werner, D. 1991. Isoflavonoid-inducible resistance to the phytoalexin glyceollin in soybean rhizobia. J. Bacteriol. 173:3432-3439.

Peters, N. K., Frost, J. W., and Long, S. R. 1986. A plant flavone, luteolin, induces expression of Rhizobium meliloti nodulation genes. Science 233:977-980

Piddock, L. J. 2006. Multidrug-resistance efflux pumps - not just for resistance. Nat. Rev. Microbiol. 4:629-636.

Pobigaylo, N., Wetter, D., Szymczak, S., Schiller, U., Kurtz, S., Meyer, F., Nattkemper, T. W., and Becker, A. 2006. Construction of a large signature-tagged mini-Tn5 transposon library and its application to mutagenesis of Sinorhizobium meliloti. Appl. Environ. Microbiol. 72:4329 4337

Price, M. N., Huang, K. H., Alm, E. J., and Arkin, A. P. 2005. A novel method for accurate operon predictions in all sequenced prokaryotes. Nucleic Acids Res. 33:880-892.

Ramos, H. J., Souza, E. M., Soares-Ramos, J. R., and Pedrosa, F. O. 2005. A new system to control the barnase expression by a NifA-dependent promoter. J. Biotechnol. 118:9-16.

Saenger, W., Orth, P., Kisker, C., Hillen, W., and Hinrichs, W. 2000. The tetracycline repressor-A paradigm for a biological switch. Angew. Chem. Int. Ed. Engl. 39:2042-2052.

Saier, M. H., Jr., and Paulsen, I. T. 2001. Phylogeny of multidrug transporters. Semin. Cell Dev. Biol. 12:205-213.

Sambrook, J., and Russel, D. W. 2001. Molecular cloning: A laboratory manual, third ed. Cold Spring Harbor Laboratory Press, Cold Spring Harbor, N.Y., U.S.A.

Santos, M. R., Cosme, A. M., Becker, J. D., Medeiros, J. M., Mata, M. F., and Moreira, L. M. 2010. Absence of functional TolC protein causes increased stress response gene expression in Sinorhizobium meliloti. BMC Microbiol. 10:180.

Santos, M. R., Marques, A. T., Becker, J. D., and Moreira, L. M. 2013. Sinorhizobium meliloti EmrR protein functions as a pleiotropic regulator and is required for efficient colonization of Medicago sativa root nodules. (this issue)

Schlüter, J. P., Reinkensmeier, J., Barnett, M. J., Lang, C., Krol, E., Giegerich, R., Long, S. R., and Becker, A. 2013. Global mapping of transcription start sites and promoter motifs in the symbiotic $\alpha$-proteobacterium Sinorhizobium meliloti 1021. BMC Genomics 14:156.

Spiers, A. J., and Bergquist, P. L. 1992. Expression and regulation of the RepA protein of the RepFIB replicon from plasmid P307. J. Bacteriol. 174:7533-7541. 
Su'etsugu, M., Nakamura, K., Keyamura, K., Kudo, Y., and Katayama, T. 2008. Hda monomerization by ADP binding promotes replicase clampmediated DnaA-ATP hydrolysis. J. Biol. Chem. 283:36118-36131.

Tahlan, K., Yu, Z., Xu, Y., Davidson, A. R., and Nodwell, J. R. 2008. Ligand recognition by ActR, a TetR-like regulator of actinorhodin export. J. Mol. Biol. 383:753-761.

Tikhonova, E. B., Dastidar, V., Rybenkov, V. V., and Zgurskaya, H. I 2009. Kinetic control of TolC recruitment by multidrug efflux complexes. Proc. Natl. Acad. Sci. U.S.A. 106:16416-16421.

Wenzel, M., Lang, K., Günther, T., Bhandari, A., Weiss, A., Lulchev, P., Szentgyörgyi, E., Kranzusch, B., and Göttfert, M. 2012. Characterization of the flavonoid-responsive regulator FrrA and its binding sites. J.
Bacteriol. 194:2363-2370

Zgurskaya, H. I., Yamada, Y., Tikhonova, E. B., Ge, Q., and Krishnamoorthy, G. 2009. Structural and functional diversity of bacterial membrane fusion proteins. Biochim. Biophys. Acta 1794:794-807.

\section{AUTHOR-RECOMMENDED INTERNET RESOURCES}

ExPASy SIB Bioinformatics resource portal: www.expasy.org Department of Energy Joint Genome Institute Integrated Microbial Genomes database: img.jgi.doe.gov/cgi-bin/edu/main.cgi

MicrobesOnline database: www.microbesonline.org 